Some Applications of the Theory of Electrolytic Dissociation to Medicine and Biology. BY W. D. BANCROFT. Electrochemical Industry, May, I903 (a lecture before the American Philosophical Society). - Certain solutions have a toxic action on certain plants or animals; it is found that the toxic action is in many cases due to a certain ion. The physiological effects of a substance are, however, a function of the degree of saturation as well as of its ionization; at equal concentrations, the ionized salt is usually more active than the un-ionized. Many reactions are accelerated by the presence of the hydrogen ion of dissociated acids; the free hydrochloric acid in the stomach assists the pepsin to act on albumen, and experiments have shown that the amount of catalytic assistance is proportional to the concentration of the hydrogen ions. Acetic acid is not dissociated I per cent. as much as hydrochloric, and, therefore, could not be substituted for it in this process of digestion. The acid in the stomach comes from the salt in the blood, and since hydrochloric acid will diffuse away from sodium chloride through a membrane, if the salt is mixed with another acid, such as lactic or acetic, the secretion of hydrochloric acid by some glands is more likely to be a case of selective diffuson of ions than any specific secretive power of the glands. The decomposition of hydrogen dioxide into water and oxygen is accelerated by colloidal metals, organic ferments and blood corpuscles. The colloidal metals have been called inorganic ferments; one milligram of platinum in 300 liters of water has a noticeable effect. It is, therefore, possible to explain why traces of arsenic in the thyroid gland are essential to health, and the necessity of iron in the system. Diffusion of liquids through senii-permeable membranes gives rise to osmotic pressures of several atmospheres, in dilute solutions; this pressure is one innportant factor in the rise of sap in trees, for it alone would theoretically cause sap to rise I to to i 50 feet. In surgery, the abdominal cavity is now washed out with a salt solution of such strength as to cause no osmosis through the cell walls with which it comes in contact; when pure water was used, the osmosis into the cells frequently caused them to become turgid and burst. This physiological salt solution should contain about 0.9 per cent. of salt, in order to be in osmotic equilibrium with the blood inside the cells.

J. W. RICHARDS.

\title{
INORGANIC CHEMISTRY.
}

The Rare Earth Crusade, What it Portends, Scientifically and Technically. By CHARles BASkerville. Science, I7, $772-781$. - This paper represents an address delivered before the Chemists' Club, New York, April 8, 1903. The author presents an historical account of the most important work on the rare 
earths from the discovery of gadolinite in 1788 to the present time.

H. N. McCoy.

The Action of Ozone, Hydrogen Peroxide, Etc., on Carbon Monoxide. By W. A. Jones. Am. Chem. J., 30, 40-50.-Carbon monoxide when mixed with air and passed over wet sticks of phosphorus is oxidized to carbon dioxide to the extent of about 2 per cent. That this result is not due to the intermediate formation of hydrogen peroxide was shown by passing carbon monoxide over phosphorus wet with a solution of hydrogen peroxide, when no oxidation occurred. Carbon monoxide was not oxidized by a 63 per cent. solution of hydrogen peroxide alone. Carbon monoxide was slowly oxidized by ozonized oxygen at the ordinary temperature and more rapidly at $250^{\circ}$. The gas contained 3.78 per cent. of ozone and was produced by a Berthelot ozonizer and a coil giving a 16 -inch spark. Electrolytic oxygen does not oxidize carbon monoxide.

H. N. McCoy.

The Action of Ozone on Carbon Monoxide. By C. E. Waters. Am. Chem. J., 30, 50-53.-Because the results obtained by Jones (preceding article) did not confirm previous work on the action of ozone on carbon monoxide, the author repeated Jones's experiments, using instead of the induction coil a Holtz machine, but otherwise employing the same apparatus. It is concluded that although ozone does not act on carbon monoxide as readily as we should expect from its apparent unsaturation, still it does cause some oxidation to carbon dioxide, depending upon the amount of ozone in the oxygen. The oxidation does not take place to an appreciable extent at the ordinary temperature.

H. N. McCoy.

On the Oxidation of Siloxicon. By EDWARD G. Acheson. Electrochem. Ind., I, 273.-Siloxicon is of variable composition, approaching, however, $\mathrm{Si}_{2} \mathrm{C}_{2} \mathrm{O}$. When it is heated, in an atmosphere rich in oxygen, it is oxidized above $1468^{\circ} \mathrm{C}$, giving silica and carbon dioxide. In a reducing atmosphere, it is stable up to very high temperatures, when it decomposes, giving carborundum and probably silicon vapor and carbon monoxide. Carborundum behaves like siloxicon when heated in an oxidizing atmosphere.

H. N. McCoy.

Notes on Recent Scientific Developments Abroad. By W. J. Hammer. J. Franklin Inst., May and June, 1903.-A lecture giving many recent facts respecting radium, polonium, actinium, selenium, and their applications.

J. W. RICHARDS.

On the Existence of a New Element Associated with Thorium. By Charies Baskervilue. J. Elisha Mitchell, Sci. Soc., I8th Year, Part 5 , pp. I-I 6 .

W. F. HiLLEBRAND. 
Arsenic Pentachloride. By Charles Baskerville and $H$. H. BENNETT. Ibid., pp. 29-3I. - The above papers have appeared under the same titles in this Journal, 23, 76I and 24, 1070.

W. F. HILIEBRAND.

\section{MINERALOGICAL AND GEOLOGICAL CHEMISTRY.}

The Ore-Deposits of Sudbury, Ontario. BY CHARLES W. Dickson. Trans. Am. Inst. Min. Eng. (Albany Meeting, Feb., I903) $65 \mathrm{pp}$. - This very thorough study is divided into two parts : (I) The relation of nickel to pyrrhotite, and (2) genesis of the Sudbury ores. Based on many experiments in concentration by himself and others, and on numerous analyses of the various products, he seems to demonstrate several facts: That the nickel occurs in the ores as peutlandite and not as an isomorphous replacement of the iron in the pyrrhotite; that the ratio of the metals to sulphur in the pentlandite is not $\mathrm{I}: \mathrm{I}$ as supposed, but II:IO, and that of the nickel to the iron also nearly II:IO (Ni:Co, 42:I); that the formula of the Sudbury pyrrhotite is generally $\mathrm{Fe}_{8} \mathrm{~S}_{9}$, though occasionally $\mathrm{Fe}_{7} \mathrm{~S}_{8}$ and $\mathrm{Fe}_{9} \mathrm{~S}_{10}$; that, while nearly all the pentlandite can be separated from the pyrrhotite by magnetic methods, its separation commercially is out of the question; that pyrrhotite and magnetite can be fairly well separated by a ro per cent. solution of nitric acid.

Wide differences of opinion obtain as to the origin of the Sudbury ores. By evidence of a largely different character from that advanced by others in favor of their secondary origin, namely, microscopical revelation of the relations between the ores and the rock minerals, the author has become fully convinced that the theory of direct igneous origin is untenable, and that their secondary origin, as in the case of the pyrrhotite deposits of Rossland, B. C., and Ducktown, Tennessee, is now placed beyond question, though a slight preliminary concentration of the metals with the intrusion of the norite is admitted as possible. A great number of reasons are given in support of his conclusion. Little can, as yet, be said regarding the paragenesis of the sulphides.

W. F. HILIEBRAND.

The Garnet Formations of the Chillagoe Copper Field, North Queensland, Australia. By GEORGE Sirth. Trans. Am. Inst. Min. Eng. (Advance extra, New York Meeting, Oct., I 903 ), I 2 pp. - Several varieties of lode-formation present themselves in this field, of which the garnet type is the most important. The writer seems to regard the garnet not as due to metamorphism of the neighboring limestove by contact with intruding granite, but as an independent injection of igneous origin. The magnetite of ten accompanying it "could then, perhaps, be explained as the result of magmatic segregation of the excess of iron pres- 